\title{
EFFECT OF TWISTED RATIO ON FLOW STRUCTURE, HEAT TRANSFER AND THERMAL IMPROVEMENT IN A CIRCULAR TUBE WITH SINGLE TWISTED TAPE
}

\author{
${ }^{1}$ Withada Jedsadaratanachai and ${ }^{2}$ Amnart Boonloi \\ ${ }^{1}$ Department of Mechanical Engineering, Faculty of Engineering, \\ King Mongkut's Institute of Technology Ladkrabang, Bangkok 10520, Thailand \\ ${ }^{2}$ Department of Mechanical Engineering Technology, College of Industrial Technology, \\ King Mongkut's University of Technology North Bangkok, Bangkok 10800, Thailand
}

Received 2013-12-21; Revised 2014-01-22; Accepted 2014-02-11

\begin{abstract}
The research presents a numerical analysis of laminar fully developed periodic flow and heat transfer in a constant temperature-surfaced circular tube with single twisted tape inserted. The twisted tape is introduced and inserted in the middle of the tested tube. The effects of twisted ratios ( $\mathrm{y} / \mathrm{W}=1,2,3,4,5$ and 6) are presented for Reynolds number (Re) values ranging from $\mathrm{Re}=100$ to 2000. The SIMPLE algorithm and periodic condition are used in the current study. The computational results are shown in the topology of flow, heat transfer and thermal improvement. It is found that the heat transfer in the circular tube with the twisted tape is more effective than that with no twisted tape inserted. The increase in the $y / W$ ratio leads to decrease in the Nusselt number and friction factor. In addition, the numerical result shows that the reduction in the $\mathrm{y} / \mathrm{W}$ ratio not only helps to create strong longitudinal vortex flows which enhance heat transfer, but also increase the pressure loss in the tested tube. The computed result reveals that the maximum value of the thermal enhancement factor, TEF is found to be 3.52 for using the twist tapes with $\mathrm{y} / \mathrm{W}=5$ at the highest Reynolds number regime.
\end{abstract}

Keywords: Periodic Flow, Tube, Laminar Flow, Heat Transfer, Pressure Loss, Twisted Tape

\section{INTRODUCTION}

The increasing necessity for saving energy and material imposed by the diminishing world resources and environmental concerns have prompted the development of more effective heat transfer equipment with improved heat transfer rates. In many industrial systems, heat must be transferred either to input energy into the system or to remove the energy produced in the system. Considering the rapid increase in energy demand world-wide, both to reducing energy lost due to ineffective use and enhancement of the energy transfer in the form of heat has become an increasingly important task for the design and operation engineers for such systems.
In recent years, many techniques have been proposed for the enhancement of the heat transfer rate. These can be classified into two main groups: Passive technique not requiring additional power sources and active technique requiring additional external power inputs. In the case of the passive technique, convection heat transfer from surfaces with attachments of different solid shapes with different geometries, such as baffles, fins, ribs, twist tapes, have been exploited, especially; twisted tape which is widely used in many industries.

The experimental investigations of twist tape for enhancing heat transfer and efficiency have been being appeared. The experimental investigation of heat transfer and friction factor characteristics for solar water heater

Corresponding Author: Withada Jedsadaratanachai, Department of Mechanical Engineering, Faculty of Engineering, King Mongkut's Institute of Technology Ladkrabang, Bangkok 10520, Thailand 
with different rotation, Clockwise (CW) and Counterclockwise (CCW) twisted tape inserted was presented by Jaisankar et al. (2009). Eiamsa-ard et al. $(2010 ; 2012)$ studied the effect of trim edges twisted tape on heat transfer and thermal performance for both laminar and turbulent regimes. They reported that the trim edges twisted tape leads to the increasing heat transfer of all cases, especially, laminar regime and the augmentation of heat transfer and thermal enhancement found to be around 12.8 and 4.88 times higher than smooth tube. Wongcharee and Eiamsa-ard (2011) exhibited the heat transfer and friction loss behavior for a combined twisted tape, alternate clockwise and counterclockwise tape. They found that the combined twisted tape provides the highest heat transfer rate around 6 times than smooth tube. The effect of modified helical screw tape; helical screw tape with space smooth surface, on pressure loss was presented by Sivashanmugam and Suresh (2007). They explained that the helical screw tape leads to the decreasing pressure loss around 2 times in comparison with normal type. Chang et al. (2011) experimental studied broken twisted tape in the test tube. They concluded that the broken twisted tape creates a higher level of turbulence flow lead to a good mixing of fluid flow than the general type. The heat transfer improvement in the square duct with combined turbulators; helical coil and twisted tape, at $\mathrm{Re}$ $=3000-18,000$ is displayed by Promvonge (2008). The combined turbulators which creating the turbulence level and give $200 \%$ of heat transfer rate was also reported.

Due to the experimental limitation, a wider range of investigations with different parameters was not feasible. But numerical simulations can be used for further investigation with the help of the correlations and data obtained from the experiments (Ektefa et al., 2011; Hafiz et al., 2011; Boonloi and Jedsadaratanachai, 2013; Jedsadaratanachai and Boonloi, 2013). Numerical experiments can give more freedom on selection of the conditions and are less costly while the experiments generally have more time consuming and higher cost but not much research on numerical methods for twisted tape. Liu et al. (2011) numerical investigated on heat transfer behavior for a twisted tape with different tape width at laminar regime. The results present that the decrease in tape width lead to reduce of the pressure loss cause of the increase in flow area in the tested tube.

As the mention earlier, the study of fully developed periodic laminar flow structure and heat transfer in a circular tube with a single twisted tape insert with different $\mathrm{y} / \mathrm{W}$ ratios has rarely been reported.
The primary objective of the research is to study numerically the heat transfer enhancement a circular tube with single twisted tape in order to understand the physical of heat transfer augmentation and flow characteristics.

The main research objectives are as follows:

- To obtain numerical solutions for a circular tube flow with single twisted tape to allow studying the effect of the $\mathrm{y} / \mathrm{W}$ ratio on heat transfer enhancement

- To try to explain the mechanism of heat transfer augmentation in a tube from the results of the numerical computations

- To verify and validate mathematical models against well documented measurements

\section{MATERIALS AND METHODS}

\subsection{Physical Domain}

A circular tube with $180^{\circ}$ clockwise twisted tape by zero thickness inserted is shown as Fig. 1. The fully developed periodic concept (Patankar et al., 1997) on both flow structure and heat transfer behavior is used for computational model. The tested fluid is air that enters the tested tube at an inlet temperature, Tin, $y$ is a pitch of twisted tape where, $\mathrm{W}$ is the tape width, the tube diameter set to $0.05 \mathrm{~m}$. The effects of twisted ratio, y/W ranging from 1 to 6 on heat transfer, pressure loss and thermal performance are studied numerically.

\subsection{Boundary Conditions}

The boundary conditions for current model are as follows:

- The periodic boundaries are used in the numerical domain

- The tested fluid is air with a temperature of 300 $\mathrm{K} \backslash(\mathrm{Pr}=0.7)$ and enter to the inlet with constant mass flow rate

- The inlet and outlet velocity profiles must be identical

- The physical properties of the air have been assumed to remain constant at average bulk temperature

- Impermeable boundary and no-slip wall conditions have been implemented over the tube wall as well as the twisted tape

- The constant temperature of the circular tube wall is maintained at $310 \mathrm{~K}$ while the twisted tape is assumed at adiabatic wall conditions 


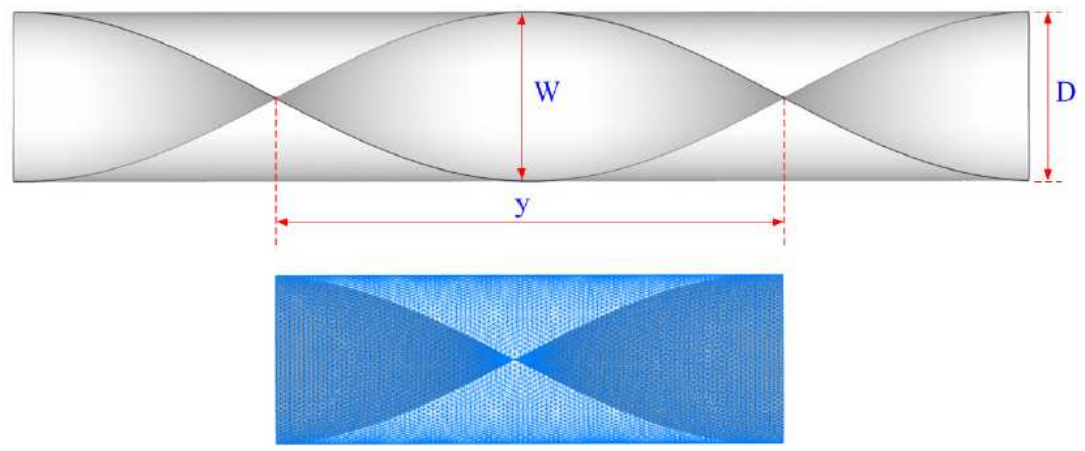

Fig. 1. Tube geometry and computational domain of periodic flow

\subsection{Numerical Models}

The numerical model for fluid flow and heat transfer in a circular tube was developed under the following assumptions:

- Steady three-dimensional fluid flow and heat transfer

- The flow is laminar and incompressible

- Constant fluid properties

- Body forces and viscous dissipation are ignored

- Negligible radiation heat transfer

\subsection{Grid independent Test}

The tetrahedral grid configuration applies for computational domain, as depicted in Fig. 1. A grid independence procedure was implemented by using the Richardson extrapolation technique over grids with different numbers of cells. The characteristics of four grids; such as 383104, 574656, 766208 and 1149312 cells, are adopted in the simulations for using the Grid Convergence Index (GCI) (Roache, 1998). The Nusselt numbers $(\mathrm{Nu})$ and the friction factors (f) of $\mathrm{y} / \mathrm{W}=1$ at $\mathrm{Re}=800$ are which demonstrates that the difference between the calculated results of 574656 and 766208 cells is less than $\pm 0.2 \%$, hence there is no such advantage in increasing the number of cells beyond this value. Therefore, the grid system with 574656 cells is adopted for the computational domain.

\subsection{Mathematical Foundation}

Based on the above assumptions, the flow in circular tube is governed by the continuity, the Navier-Stokes and the energy equations. In the Cartesian tensor system these equations can be written as follows.

Continuity Equation 1:
$\frac{\partial}{\partial_{\mathrm{Xi}}}\left(\rho u_{\mathrm{i}}\right)=0$

Momentum Equation 2:

$\frac{\partial\left(\rho u_{i} u_{j}\right)}{\partial_{X j}}=-\frac{\partial_{p}}{\partial_{X i}}+\frac{\partial}{\partial_{X j}}\left[\mu\left(\frac{\partial u_{i}}{\partial_{X j}}+\frac{\partial u_{j}}{\partial_{X i}}\right)\right]$

Energy Equation 3:

$\frac{\partial}{\partial_{\mathrm{Xi}}}\left(\rho u_{\mathrm{i}} \mathrm{T}\right)=\frac{\partial}{\partial_{\mathrm{Xj}}}\left(\Gamma \frac{\partial \mathrm{T}}{\partial_{\mathrm{Xj}}}\right)$

where, $\Gamma$ is the thermal diffusivity and is given by Equation 4:

$\Gamma=\frac{\mu}{\mathrm{P}_{\mathrm{r}}}$

Apart from the energy equation discretized by the QUICK scheme, the governing equations were discretized by the Second Order Upwind (SOU) scheme, decoupling with the SIMPLE algorithm and solved by using a finite volume approach (Patankar, 1980). The solutions were considered to be converged when the normalized residual values were less than $10^{-5}$ for all variables but less than $10^{-9}$ only for the energy equation.

Four parameters of interest in the present work are the Reynolds number, friction factor, Nusselt number and thermal enhancement factor. The Reynolds number is defined as Equation 5:

$$
\operatorname{Re}=\rho \bar{u} \mathrm{D} / \mu
$$


The friction factor, $\mathrm{f}$ is computed by pressure drop, $\Delta p$ across the length of the periodic tube, $L$ as Equation 6:

$\mathrm{f}=\frac{(\Delta \mathrm{p} / \mathrm{L}) \mathrm{D}}{\frac{1}{2} \rho \overline{\mathrm{u}}^{2}}$

The heat transfer is measured by the local Nusselt number which can be written as Equation 7:

$$
\mathrm{Nu}_{\mathrm{x}}=\frac{\mathrm{h}_{\mathrm{x}} \mathrm{D}}{\mathrm{k}}
$$

The average Nusselt number can be obtained by Equation 8:

$$
\mathrm{Nu}=\frac{1}{\mathrm{~A}} \int \mathrm{Nu}_{\mathrm{x}} \partial \mathrm{A}
$$

The Thermal Enhancement Factor (TEF) is defined as the ratio of the heat transfer coefficient of an augmented surface, $h$ to that of a smooth surface, h0, at an equal pumping power and given by Equation 9:

$$
\mathrm{TEF}=\left.\frac{\mathrm{h}}{\mathrm{h}_{0}}\right|_{\mathrm{pp}}=\left.\frac{\mathrm{Nu}}{\mathrm{Nu}_{0}}\right|_{\mathrm{pp}}=\left(\mathrm{Nu} / \mathrm{Nu}_{0}\right) /\left(\mathrm{f} / \mathrm{f}_{0}\right)^{1 / 3}
$$

where, $\mathrm{Nu}_{0}$ and $\mathrm{f}_{0}$ stand for Nusselt number and friction factor for the smooth tube, respectively.

\section{RESULTS AND DISCUSSION}

\subsection{Validation of Smooth Circular Tube}

The values on both $\mathrm{Nu}$ and $\mathrm{f}$ are compared between the present prediction and the exact solution under similar operating conditions. The result is found to be in excellent agreement with exact solution values obtained from the open literature (Incropera and Dewitt, 2006) for both the $\mathrm{Nu}$ and f, less than $\pm 1.25 \%$ deviation as shown in Table 1. Equation (10 and 11) show the exact solution of $\mathrm{Nu}$ and $\mathrm{f}$ for fully developed laminar flows over smooth circular tube with constant wall temperature condition:

$$
\begin{aligned}
& \mathrm{Nu}_{0}=3.66 \\
& \mathrm{f}_{0}=64 / \mathrm{Re}
\end{aligned}
$$

\subsection{Effect of Re}

The effects of Reynolds number on flow behavior and heat transfer are presented in terms of streamlines in the transverse planes, contours of temperature and $\mathrm{Nu}_{\mathrm{x}}$ as Fig. 2 and 3.

\subsection{Flow Structure}

The plot of streamlines in transverse planes with contour temperature is displayed as Fig. 2a to $\mathbf{c}$ for $\mathrm{Re}=$ 200, 1000 and 2000, respectively, at similar twisted ratio, $\mathrm{y} / \mathrm{W}=3.0$. As the figures, the streamlines in transverse planes for all cases are found to be similar pattern, the main core flow appears and moves depending on the twisted tape configuration but different on vortex intensity. The $\mathrm{Re}=2000$ shows the highest while the $\mathrm{Re}$ $=200$ provides the lowest value of the vortex intensity level. In addition, the rise of Re results in a higher of intensity level of flow structure.

\subsection{Heat Transfer}

The effects of heat transfer are shown by the plot of contours temperature and contours $\mathrm{Nu}_{\mathrm{x}}$ as Fig. 2 and 3, respectively. The contours of temperature for $\operatorname{Re}=200$, 1000 and 2000 are presented in Fig. 2a to c, respectively. As the figures, the $\mathrm{Re}=2000$ gives the excellence mixing of temperature between core flow and near the wall regime, while the $\mathrm{Re}=200$ shows rarely mixing of fluid flow. The red contours of temperature that closing $310 \mathrm{~K}$, is appearing clearly on three planes at $\operatorname{Re}=200$, especially, near the wall regimes, because of the lower level of vortex intensity and not good mixing fluid temperature. The result shows that the rise of Re effects for good mixing of fluid flow over the twisted tape tube.

The contours plot of $\mathrm{Nu}_{\mathrm{x}}$ for $\mathrm{Re}=200,1000$ and 2000 with similar $y / W=3$ are presented as Fig. 3a to c, respectively. The highest heat transfer is found at the highest Reynolds number, $\mathrm{Re}=2000$, that the contours of $\mathrm{Nu}_{\mathrm{x}}$ shows uniformly over the tube wall while the $\mathrm{Re}$ $=200$, gives the lowest heat transfer rate. The result reveals that the higher in $\mathrm{Re}$ lead to the increase in heat transfer over the twisted tape tube.

\subsection{Effect of $y / W$ Ratio}

The effects of six different twisted ratios, $\mathrm{y} / \mathrm{W}=1,2$, $3,4,5$ and 6 are presented on both flow configuration and heat transfer behavior as Fig. 4-7 for streamlines in transverse planes, contours of temperature, contours temperature in the middle of the module and contours $\mathrm{Nu}_{\mathrm{x}}$, respectively. 
Withada Jedsadaratanachai and Amnart Boonloi / Journal of Mathematics and Statistics 10 (1): 80-91, 2014

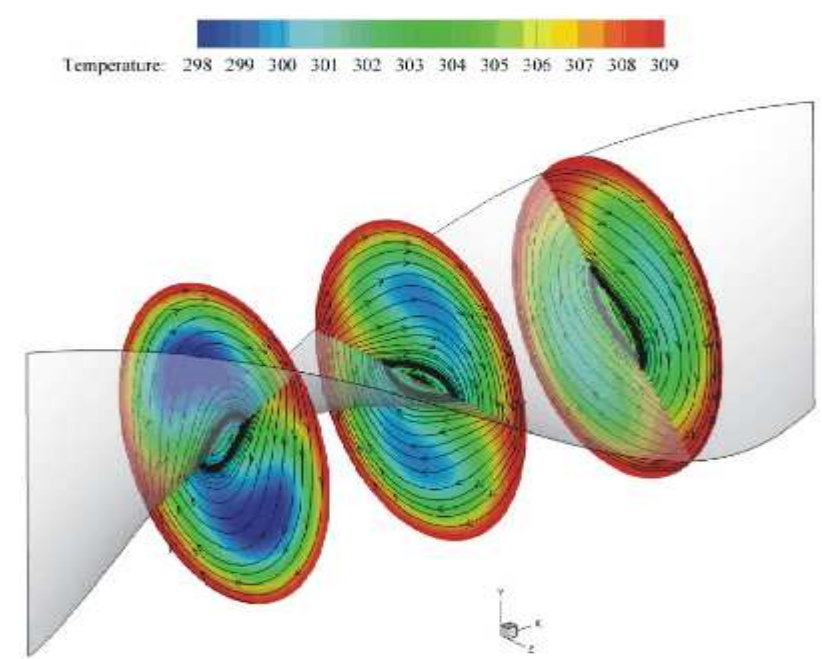

(a)

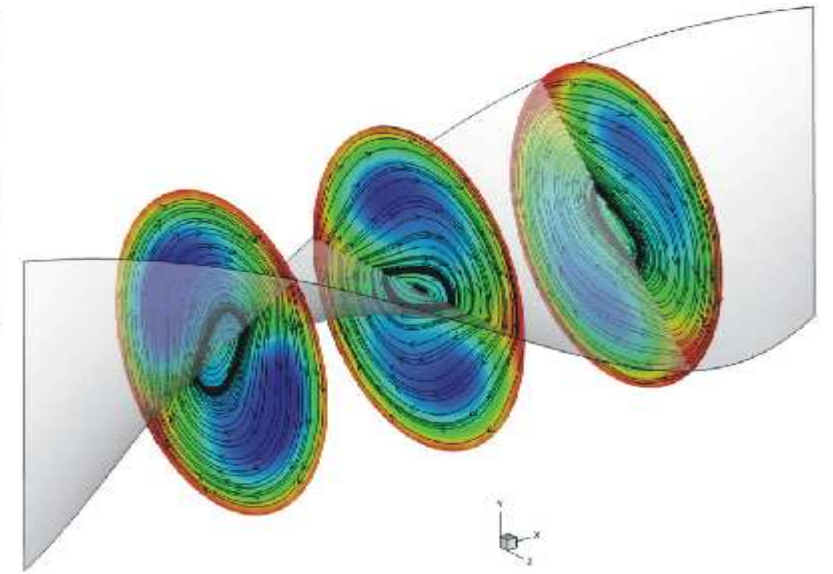

(b)

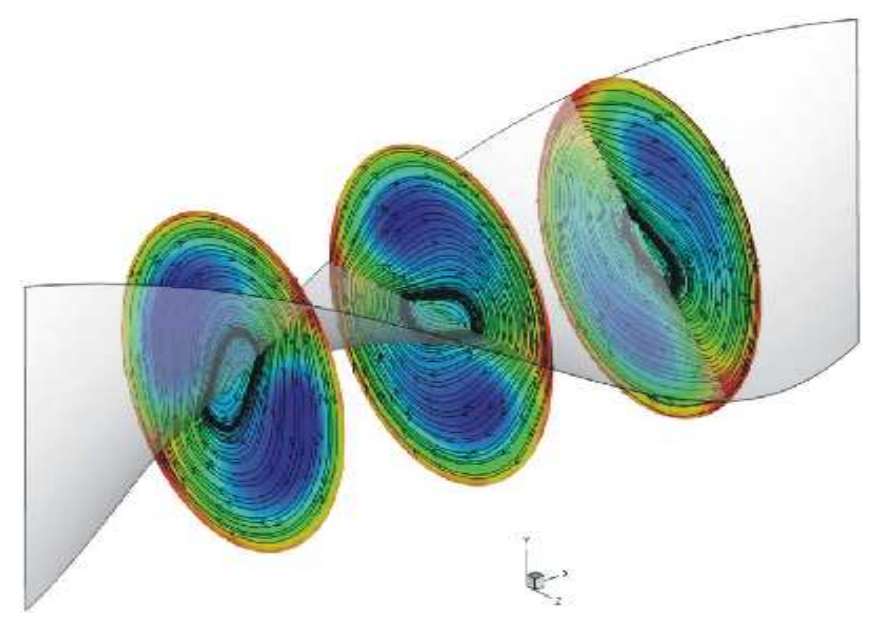

(c)

Fig. 2. The streamlines in transverse planes with contours temperature for (a) $\operatorname{Re}=200$, (b) $\operatorname{Re}=1000$ and (c) $\operatorname{Re}=2000$ at $y / W=3$

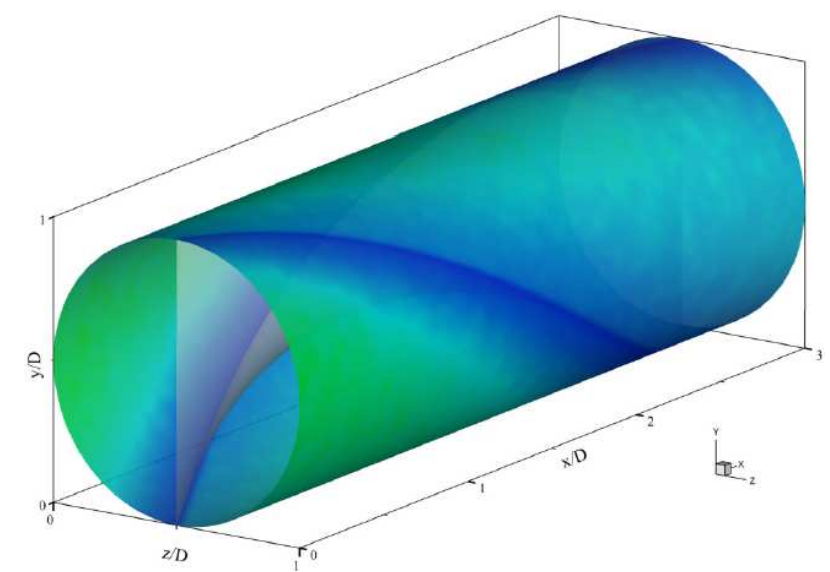

(a)

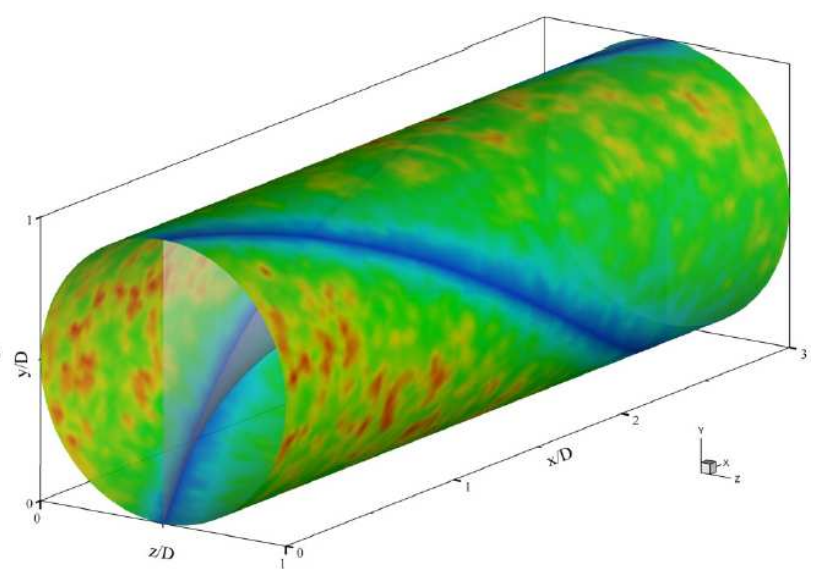

(b) 
Withada Jedsadaratanachai and Amnart Boonloi / Journal of Mathematics and Statistics 10 (1): 80-91, 2014

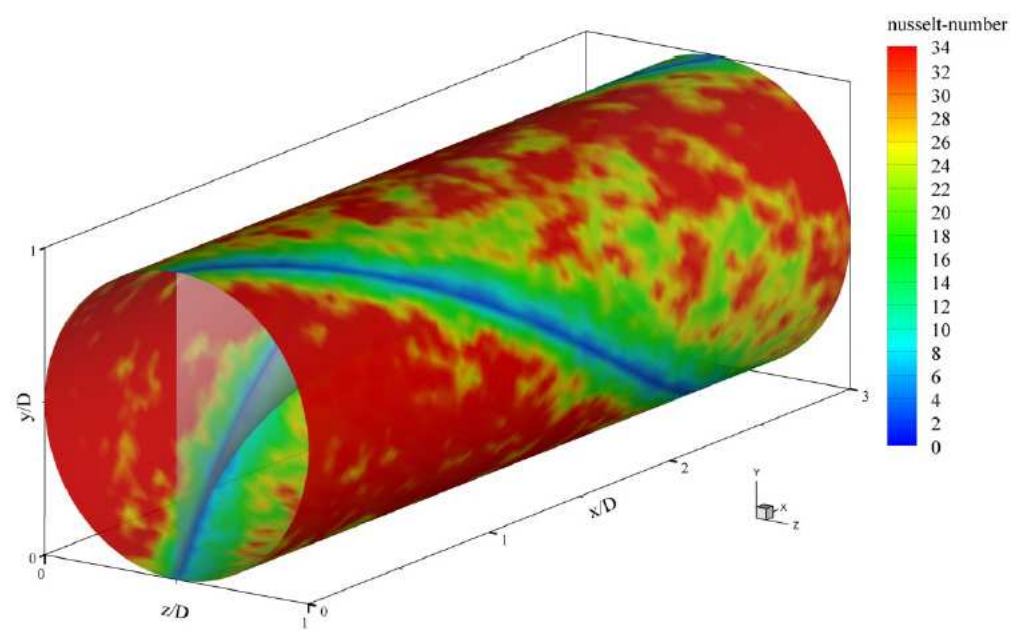

(c)

Fig. 3. $\mathrm{Nu}_{\mathrm{x}}$ contours for (a) $\mathrm{Re}=200$, (b) $\mathrm{Re}=1000$ and (c) $\mathrm{Re}=2000$ at $\mathrm{y} / \mathrm{W}=3$

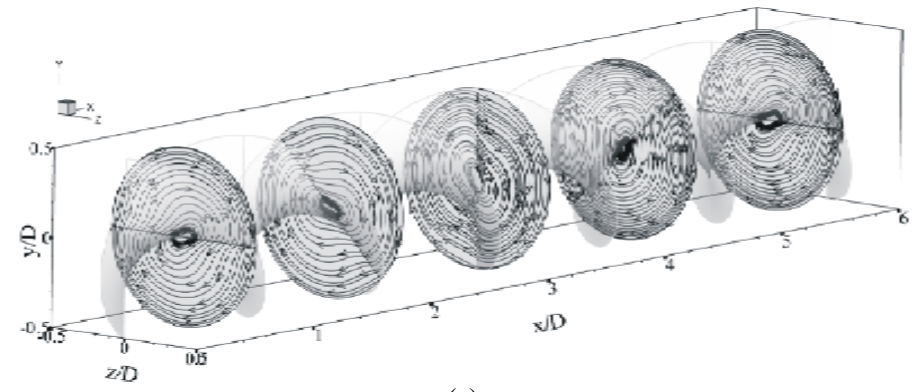

(a)

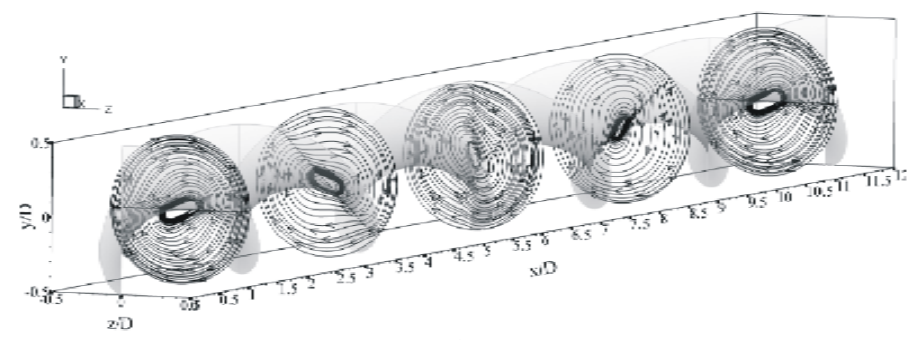

(b)

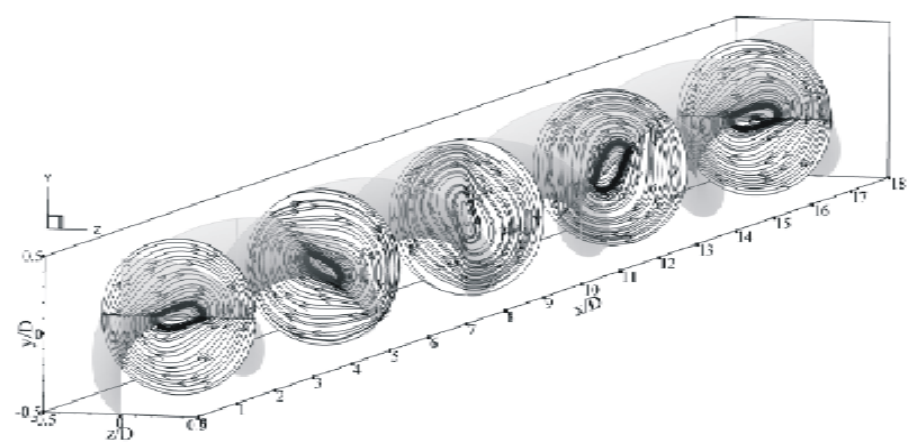

(c) 


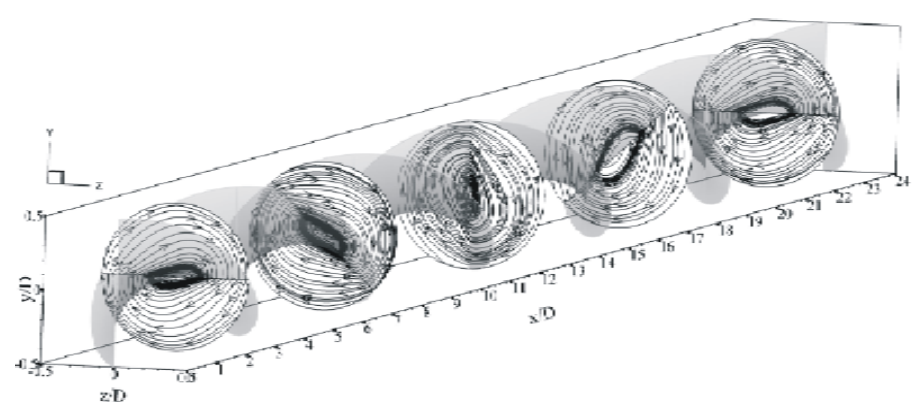

(d)

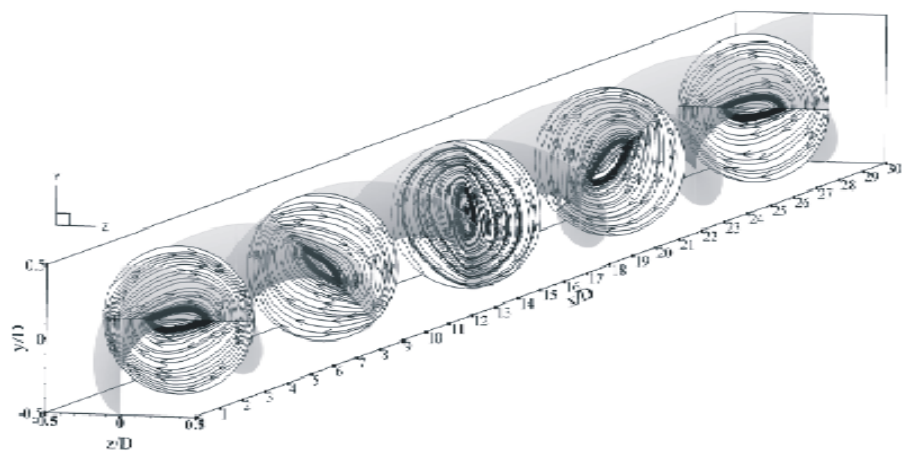

(e)

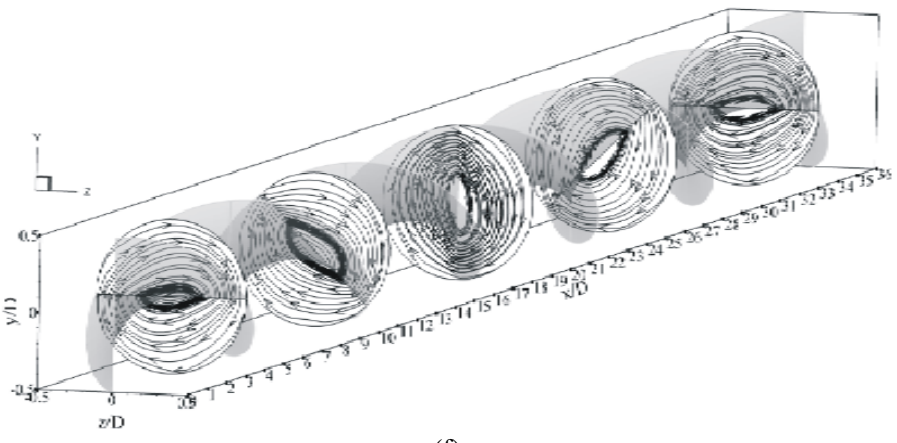

(f)

Fig. 4. Streamlines in transverse planes for (a) $y / W=1$, (b) $y / W=2$, (c) $y / W=3$, (d) $y / W=4$, (e) $y / W=5$ and (f) $y / W=6$ at $\mathrm{Re}=1200$

\subsection{Flow Structure}

The flow configurations of twisted tape in terms of streamlines in transverse planes are displayed as Fig. 4a, e and $\mathbf{f}$ for twisted ratios, $\mathrm{y} / \mathrm{W}=1,2,3,4,5$ and 6 , respectively. As the figures, the flow configurations for all cases are performed similar prototype but different in intensity level. The result shows that a higher of twisted ratio provides the decreasing level of vortex strength. In addition, the $\mathrm{y} / \mathrm{W}=1$ leads to the highest level of intensity while the $\mathrm{y} / \mathrm{W}=6$ provides the lowest form.

\subsection{Heat Transfer}

The contours temperature in transverse planes for twisted tape are presented as Fig. 5a to e and for $\mathrm{y} / \mathrm{W}=1,2,3,4,5$ and 6 , respectively. The use of twisted tape leads to better mixing for testing fluid flow over the smooth circular tube and also increases heat transfer rate in the tested tube of all cases. The highest heat transfer rate is found to be at $y / W=1$, while the $y / W=6$ creates the terribly mixing and the lowest heat transfer rate. 


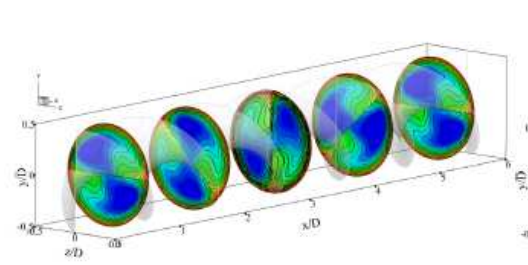

(a)

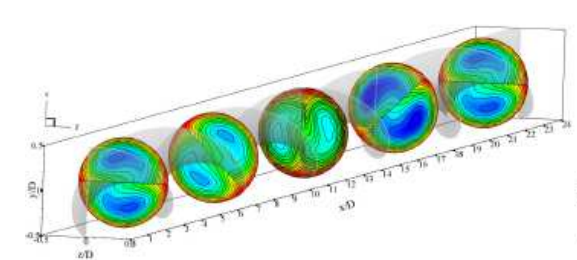

(d)

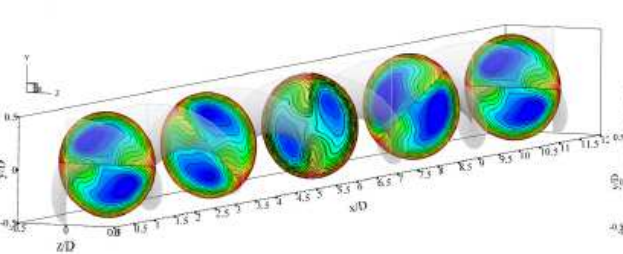

(b)

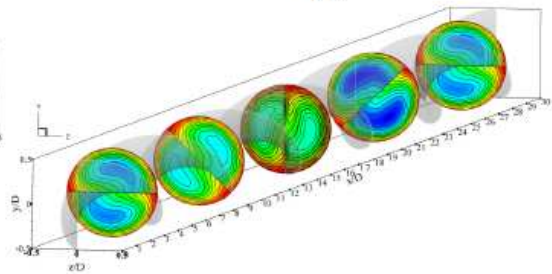

(e)

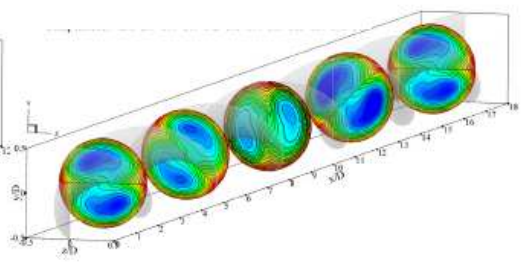

(c)

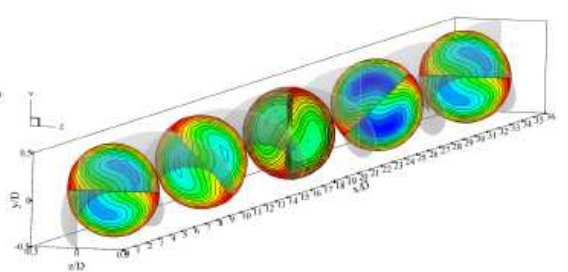

(f)

Fig. 5. Contours temperature in transverse planes for (a) $y / W=1$, (b) $y / W=2$, (c) $y / W=3$, (d) $y / W=4$, (e) $y / W=5$ and (f) $y / W=6$ at $\operatorname{Re}=1200$

Table 1. Validation of smooth circular tube

\begin{tabular}{|c|c|c|c|c|c|c|}
\hline \multirow[b]{2}{*}{$\mathrm{Re}$} & \multicolumn{2}{|c|}{ Exact solution } & \multicolumn{2}{|c|}{ Present prediction } & \multicolumn{2}{|c|}{ Error $(\%)$} \\
\hline & $\mathrm{Nu}$ & $\mathrm{f}$ & $\mathrm{Nu}$ & f & $\mathrm{Nu}$ & $f$ \\
\hline 100 & 3.66 & 0.6400 & 3.646 & 0.63950 & 0.38251 & 0.07813 \\
\hline 200 & 3.66 & 0.3200 & 3.645 & 0.32000 & 0.40984 & 0.00000 \\
\hline 300 & 3.66 & 0.2133 & 3.656 & 0.21290 & 0.10929 & 0.18753 \\
\hline 400 & 3.66 & 0.1600 & 3.649 & 0.16120 & 0.30055 & -0.75000 \\
\hline 500 & 3.66 & 0.1280 & 3.651 & 0.12790 & 0.24590 & 0.07812 \\
\hline 600 & 3.66 & 0.1067 & 3.662 & 0.10650 & -0.05464 & 0.18744 \\
\hline 800 & 3.66 & 0.0800 & 3.662 & 0.08100 & -0.05464 & -1.25000 \\
\hline 1000 & 3.66 & 0.0640 & 3.656 & 0.06420 & 0.10929 & -0.31250 \\
\hline 1200 & 3.66 & 0.0533 & 3.658 & 0.05290 & 0.05464 & 0.75047 \\
\hline 1600 & 3.66 & 0.0400 & 3.666 & 0.04010 & -0.16393 & -0.25000 \\
\hline 2000 & 3.66 & 0.0320 & 3.667 & 0.03211 & -0.19126 & -0.34375 \\
\hline
\end{tabular}

In the Fig. 5a, the contours temperature near the tube wall show the thin layer of red contours that because of a good mixing from twisted tape at $\mathrm{y} / \mathrm{W}=1$. The comparison of temperature contours in transverse planes at the middle of the module is plotted as Fig. 6. The result reveals that the reduction of the twisted ratio in the tested tube tends to increase in a higher mixing level of the fluid flow and heat transfer rate.

$\mathrm{Nu}_{\mathrm{x}}$ contours over the tube wall for the twisted tape circular tube are shown in the Fig. 7a to e and $\mathrm{f}$ for $\mathrm{y} / \mathrm{W}$ $=1,2,3,4,5$ and 6 , respectively. It is found that the use of twisted tape inserted in the circular tube leads to a higher heat transfer rate than the smooth tube with no twisted tape in all cases studied. The heat transfer behavior for all cases is found to be similarly observing by the contour pattern over the tube wall.

\subsection{Performance Evaluation}

The performance evaluations are presented in terms of heat transfer, pressure drop and thermal enhancement factor.

\subsection{Heat Transfer}

Heat transfer behavior is presented by considering the variation of $\mathrm{Nu} / \mathrm{Nu}_{0}$ versus $\mathrm{y} / \mathrm{W}$ ratios as Fig. 8. In the figure, the $\mathrm{Nu} / \mathrm{Nu}_{0}$ tends to increase with the rise of $\mathrm{Re}$ and with the decrease in twisted ratio, y/W. 
Withada Jedsadaratanachai and Amnart Boonloi / Journal of Mathematics and Statistics 10 (1): 80-91, 2014
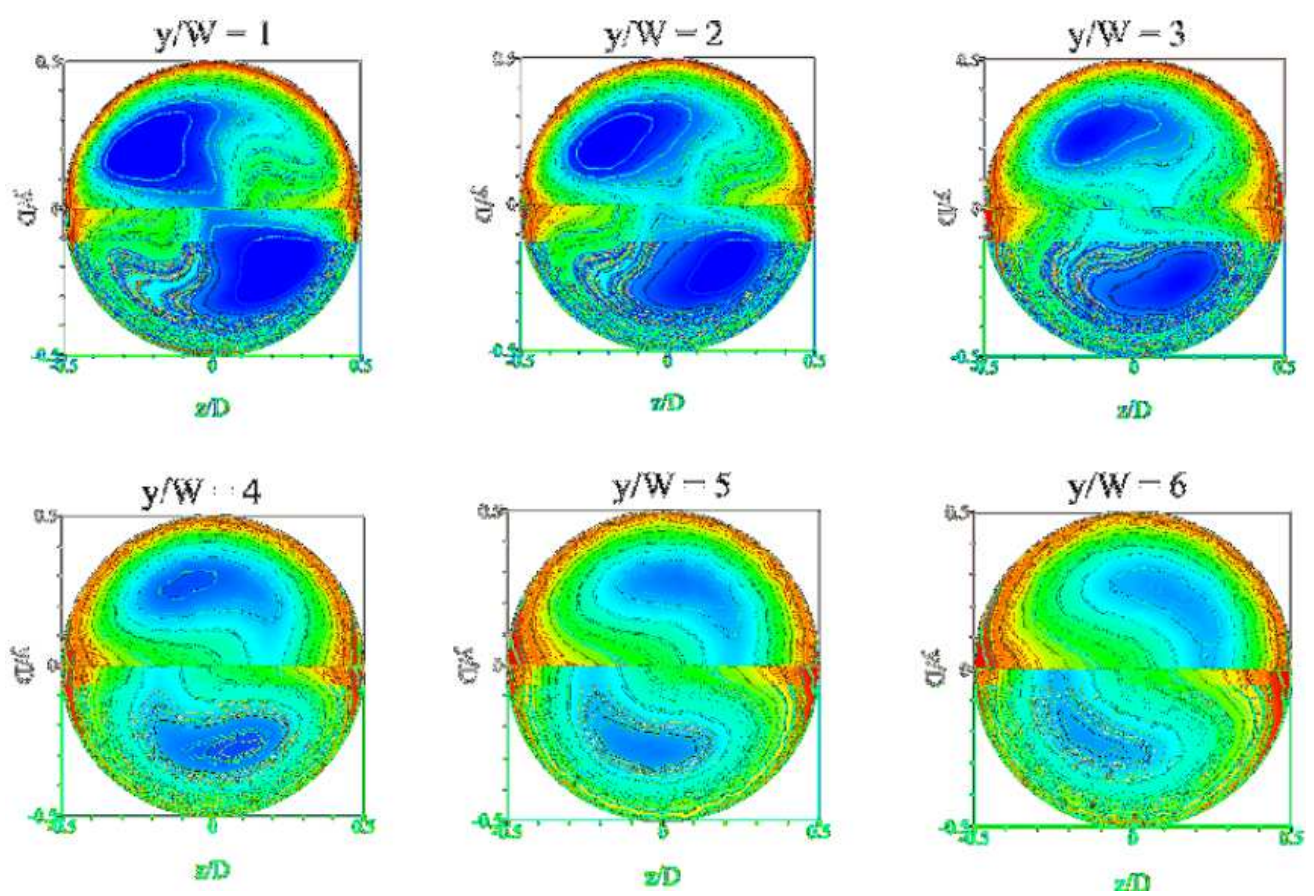

Fig. 6. Contours temperature in transverse planes at the middle of the module for $\operatorname{Re}=1200$

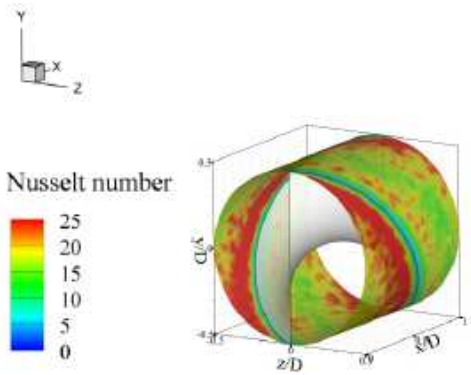

(a)

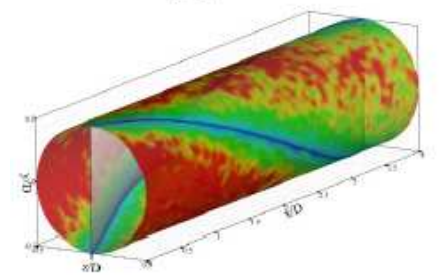

(d)

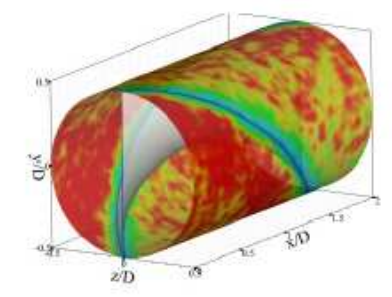

(b)

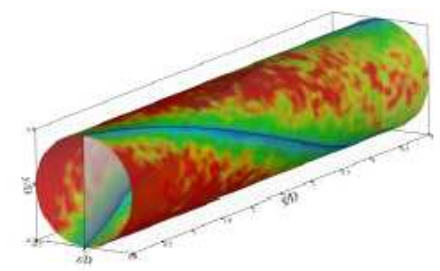

(e)

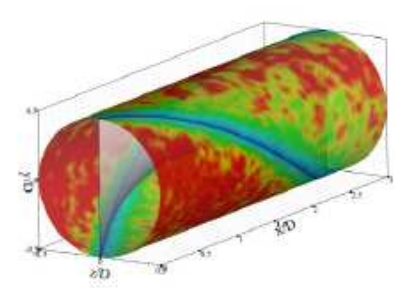

(c)

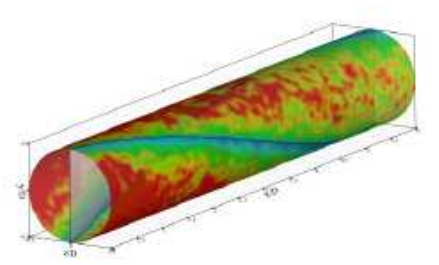

(f)

Fig. 7. Contours $\mathrm{Nu}_{\mathrm{x}}$ for (a) $\mathrm{y} / \mathrm{W}=1$, (b) $\mathrm{y} / \mathrm{W}=2$, (c) $\mathrm{y} / \mathrm{W}=3$, (d) $\mathrm{y} / \mathrm{W}=4$, (e) $\mathrm{y} / \mathrm{W}=5$ and (f) $\mathrm{y} / \mathrm{W}=6$ at $\mathrm{Re}=1200$ 
Withada Jedsadaratanachai and Amnart Boonloi / Journal of Mathematics and Statistics 10 (1): 80-91, 2014

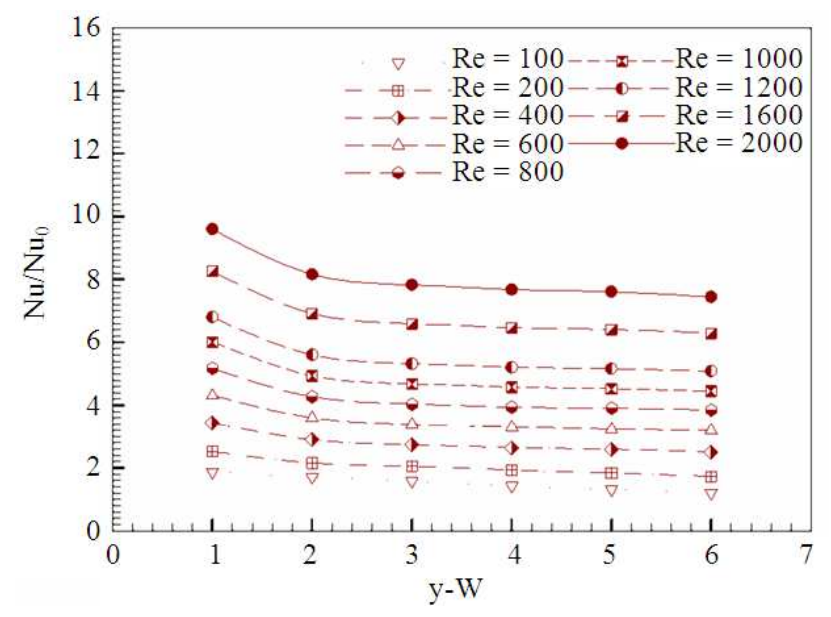

Fig. 8. Variation of $\mathrm{Nu} / \mathrm{Nu} 0$ with $\mathrm{y} / \mathrm{W}$ for twisted tape at various $\mathrm{Re}$

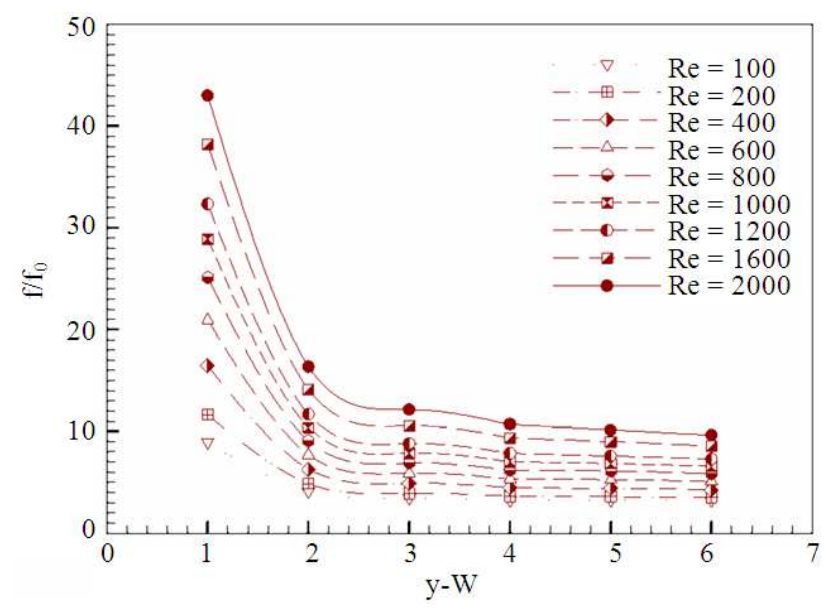

Fig. 9. Variation of $\mathrm{f} / \mathrm{f}_{0}$ with $\mathrm{y} / \mathrm{W}$ for twisted tape at various $\mathrm{Re}$

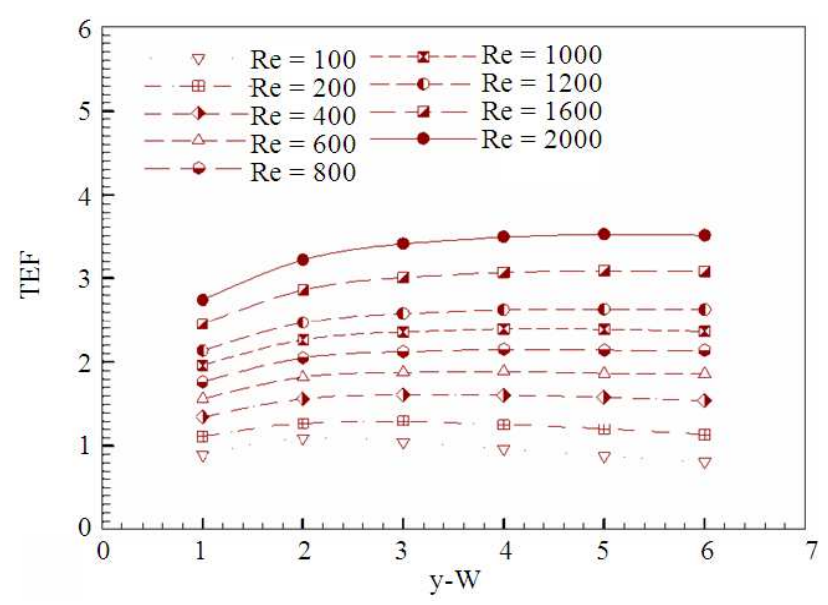

Fig. 10. Variation of TEF with $y / W$ for twisted tape at various $\mathrm{Re}$ 
At $\mathrm{y} / \mathrm{W}=1-2$, the decreasing rate of $\mathrm{Nu} / \mathrm{Nu}_{0}$ is found to be the highest value, when $\mathrm{y} / \mathrm{W}>2.0$, the $\mathrm{Nu} / \mathrm{Nu}_{0}$ gives slightly decrease.

The use of twisted tape at $\mathrm{Re}=100-2000$ for $\mathrm{y} / \mathrm{W}=$ 1-6 enhances the heat transfer around 1-10 times in comparison to the smooth tube. The maximum heat transfer is found at $\mathrm{y} / \mathrm{W}=1$ at the highest Reynolds number, $\operatorname{Re}=2000$.

\subsection{Pressure Loss}

The use of twisted tape inserted in circular tube not only increases heat transfer rate, but also increases in pressure loss. The variation of the friction factor ratio with $y / W$ is depicted in Fig. 9. It is found that the $f / f_{0}$ decreases with the rises of $\mathrm{y} / \mathrm{W}$ value. In range of $\mathrm{y} / \mathrm{W}=$ $1-2$, the $f / f_{0}$ value is extremely decreasing, while $y / W>4$, the $f / f_{0}$ provides slightly reduce. The higher pressure loss is appeared by increasing Reynolds number and with the reduction of twisted ratio.

The higher of $\mathrm{f} / \mathrm{f}_{0}$ is around 3-44 times than the smooth tube for using twisted tape ratio in the range from 1 to 6 with $\operatorname{Re}=100-2000$. The maximum friction factor ratio is found at $\mathrm{y} / \mathrm{W}=1.0$ and $\mathrm{Re}=2000$. In addition, the peak of $\mathrm{y} / \mathrm{W}$ helps to reduce the pressure loss causing the lower level of vortex intensity.

\subsection{Thermal Enhancement Factor}

The variation of thermal enhancement factor, TEF with $\mathrm{y} / \mathrm{W}$ values is indicated as Fig. 10. The use of twisted tape inserted in circular tube in the range studied gives TEF values around 0.8-3.51. The case of $\mathrm{Re}=$ 2000 at $\mathrm{y} / \mathrm{W}=5$ shows the maximum $\mathrm{TEF}$ value. Although, $y / \mathrm{W}=1$ provides the highest heat transfer rate but it also gives the highest friction factor, therefore, the optimization between enhancing heat transfer and pressure loss is found at $\mathrm{y} / \mathrm{W}=5$.

\section{CONCLUSION}

Fully developed periodic flow and heat transfer behavior in a circular tube with twisted taped inserted are studied numerically. The use of twisted tape with twisted ratios, $\mathrm{y} / \mathrm{W}=1-6$ for Reynolds number, $\mathrm{Re}=100-2000$ is to create vortex flow over the tested tube lead to increase in heat transfer and thermal performance in the heat exchanger. The rise of $\mathrm{Re}$ value with the decrease $\mathrm{y} / \mathrm{W}$ ratio results in the increase of heat transfer and pressure loss. The $\mathrm{y} / \mathrm{W}=1$ shows the highest on both heat transfer and pressure loss while the $\mathrm{y} / \mathrm{W}=6$ case gives the lowest values. The enhancement of heat transfer is found to be about 1-10 times higher that smooth tube. Although, the use of twisted tape help to increase heat transfer but also increase in pressure loss. The pressure loss in rang studied is appearing around 344 times in comparison with plain tube. In addition, the maximum $\mathrm{TEF}$ is about 3.51 for $\mathrm{y} / \mathrm{W}=5$ at the highest Reynolds number.

\section{ACKNOWLEDGEMENT}

The financial support of the research is supported by King Mongkut's Institute of Technology Ladkrabang (KMITL) research fund. The authors would like to thank Assoc. Prof. Dr Pongjet Promvonge and Mr. Pitak Promthaisong for suggestion.

\section{REFERENCES}

Boonloi, A. and W. Jedsadaratanachai, 2013. 3D numerical study on laminar forced convection in vbaffled square channel. Am. J. Applied Sci., 10: 1287-1297. DOI: 10.3844/ajassp.2013.1287.1297

Chang, S.W., T.L. Yang and T.M. Liou, 2011. Heat transfer and pressure drop in tube with broken twisted tape insert. Exp. Thermal Fluid Sci., 32: 489-501. DOI: 10.1016/j.ijthermalsci.2008.03.001

Eiamsa-ard, S., C. Thianpong and P. Eiamsa-ard, 2010. Turbulent heat transfer enhancement by counter/coswirling flow in a tube fitted with twin twisted tapes. Exp. Thermal Fluid Sci., 34: 53-62. DOI: 10.1016/j.expthermflusci.2009.09.002

Eiamsa-ard, S., C. Thianpong, P. Eiamsa-ard and P. Promvonge, 2012. Effect of perforated twistedtapes with parallel wings on heat transfer enhancement in a heat exchanger tube. Energy Proc., 14: 1117-1123. DOI: 10.1016/j.egypro.2011.12.1064

Ektefa, M., F. Sidi, H. Ibrahim, M.A. Jabar and S. Memar, 2011. A comparative study in classification techniques for unsupervised record linkage model. J. Comput. Sci., 7: 341-347. DOI: 10.3844/jcssp.2011.341.347

Hafiz, D.A., W.M. Sheta, S. Bayoumi and B.A.B. Youssef, 2011. A new approach for 3D range image segmentation using gradient method. J. Comput. Sci., 7: 475-487. DOI: 10.3844/jcssp.2011.475.487

Incropera, F. and P.D. Dewitt, 2006. Introduction to Heat Transfer. 5th Edn., John Wiley and Sons Inc, ISBN10: 9780470508695. 
Jaisankar, S., T.K. Radhakrishnan, K.N. Sheeba and S. Suresh, 2009. Experimental investigation of heat transfer and friction factor characteristics of thermosyphon solar water heater system fitted with spacer at the trailing edge of Left-Right twisted tapes. Energy Conver. Manage., 50: 2638-2649. DOI: 10.1016/j.enconman.2009.06.019

Jedsadaratanachai, W. and A. Boonloi, 2013. Energy performance improvement, flow behavior and heat transfer investigation in a circular tube with vdownstream discrete baffles. J. Math. Stat., 9: 339348. DOI: 10.3844/jmssp.2013.339.348

Liu, W., J. Guo, A. Fan and X. Zhang, 2011. A numerical study on heat transfer and friction factor characteristics of laminar flow in a circular tube fitted with centercleared twisted tape. Int. J. Thermal Sci., 50: 12631270. DOI: 10.1016/j.ijthermalsci.2011.02.010

Patankar, S.V., 1980. Numerical Heat Transfer and Fluid Flow. 1st Edn., McGraw-Hill, New York, ISBN-10: 0891165223, pp: 214.

Patankar, S.V., C.H. Liu and E.M. Sparrow, 1997. Fully developed flow and heat transfer in ducts having streamwise-periodic variations of cross-sectional area. ASME J. Heat Trans., 99: 180-186. DOI: $10.1115 / 1.3450666$
Promvonge, P., 2008. Thermal augmentation in circular tube with twisted tape and wire coil turbulators. Energy Conver. Manage., 49: 2949-2955. DOI: 10.1016/j.enconman.2008.06.022

Roache, P.J., 1998. Verification and Validation in Computational Science and Engineering. 1st Edn., Hermosa Publishers, Albuquerque, NM, ISBN-10: 0913478083, pp: 464.

Sivashanmugam, P. and S. Suresh, 2007. Experimental studies on heat transfer and friction factor characteristics of laminar flow through a circular tube fitted with regularly spaced helical screw-tape inserts. Exp. Thermal Fluid Sci., 31: 301- 308. DOI: 10.1016/j.expthermflusci.2006.05.005

Wongcharee, K. and S. Eiamsa-ard, 2011. Friction and heat transfer characteristics of laminar swirl flow through the round tubes inserted with alternate clockwise and counter-clockwise twisted- tapes. Int. Commun. Heat Mass Trans., 38: 348-352. DOI: 10.1016/j.icheatmasstransfer.2010.12.007 